\title{
DIVERSIDAD DE ENEMIGOS NATURALES DE PULGONES EN CULTIVOS DE LECHUGA
}

\section{Morales ${ }^{1}$, J. M. Aguado ${ }^{1}$ M. Nebreda', B. M. Diaz, A. Romero ${ }^{1}$, A. Pineda ${ }^{2}$, Ma A. Marcos-García ${ }^{2}$, A. Fereres ${ }^{1}$}

INTERRELACIONES INSECTO-PATÓGENO-PLANTA Y SUS AGENTES DE BIOCONTROL (IPAB), UNIDAD ASOCIADA AL CSIC (CONSEjo Superior de InVESTigaCiOnes Científicas), Universidad DE AliCANTE.

1 InSTITUTO DE CienCIAS Agrarias. CSIC

2 CIBIO, Universidad DE AlicANTE

\section{INTRODUCCIÓN}

El uso masivo de insecticidas dirigidos a aumentar los rendimientos de producción, produce una serie de efectos secundarios muy perjudiciales para el medio ambiente, como son la contaminación de las aguas y de los suelos, los residuos en los alimentos, la potenciación de plagas secundarias, la aparición de resistencias a dichos insecticidas y la eliminación de polinizadores y fauna autóctona.

Para intentar disminuir la dependencia a los productos fitosanitarios, se deben potenciar otras estrategias de lucha contra plagas y una de ellas es el control biológico. Este control está basado en el uso de organismos vivos para reducir la densidad de población o el impacto de una determinada plaga (EILENBERG et al., 2001).

Un enemigo natural es un organismo vivo que vive a expensas de otro nocivo, y que contribuye a limitar la población de su huésped o de su presa. Los enemigos naturales son aquellos organismos que matan, reducen el potencial reproductor, o reducen el número de individuos de un determinado fitófago (FLINT \& DREISTADT, 1999). Para poder utilizarlos con éxito en la lucha contra las plagas hay que conocer muy bien su biología y ecología. El objetivo de este trabajo se ha enfocado a determinar cuáles son los enemigos naturales más abundantes de las principales plagas de pulgones que atacan los cultivos de lechuga de la zona centro de España.

Hay tres grandes grupos de enemigos naturales de pulgones: depredadores, parasitoides y patógenos.

Los depredadores son organismos que se alimentan de otros individuos (sus presas) a lo largo de su vida. Algunos depredadores están muy especializados y se alimentan de una o pocas especies estrechamente relacionadas, pero la mayoría de los depredadores son más generalistas y se alimentan de una gran variedad de insectos.

Los parasitoides son organismos con una mayor especificidad por su hospedador, donde el parasitoide desarrolla todo su ciclo vital. Este parasitismo se realiza solamente durante su fase juvenil, siendo los adultos de vida libre. Mientras que los parásitos suelen 
presentar un tamaño mucho menor que sus hospedadores, los adultos de muchas especies de parasitoides tienen un tamaño parecido al hospedador.

Los patógenos son microorganismos parásitos que causan enfermedades en su huésped (el insecto, en este caso). Pertenecen a este grupo los virus, las bacterias y los hongos entomopatógenos.

\section{MATERIAL Y MÉTODOS}

Este ensayo se llevó a cabo durante el otoño de 2003 y la primavera de 2004 en la finca experimental "La Poveda" del CSIC situada en Arganda del Rey (Madrid).

Se muestreó una superficie de cultivo de lechugas 319,2 $\mathrm{m}^{2}$ en el otoño, y otra de $1.092 \mathrm{~m}^{2}$ en primavera. Las lechugas utilizadas pertenecían a las variedades de otoño Moratina y de primavera Aitana y fueron suministradas en estado de plántula por la finca "Hortícolas El Sevillano". Posteriormente fueron transplantadas en La Poveda empleando un marco de plantación de 40 x 40 .

Cada semana se muestrearon 40 lechugas en Otoño y 160 en Primavera, tomadas al azar siguiendo un recorrido en zig-zag por la superficie de muestreo. Los muestreos se realizaron inspeccionando todas las hojas de cada planta y anotando el número de individuos adultos (alados y ápteros) y ninfas en el caso de las especies de pulgones, y el número de individuos de cada especie en el caso de los enemigos naturales de pulgones. En este último caso se recogieron individuos de las especies de depredadores y parasitoides más frecuentes (Sírfidos, Antocóridos, Míridos, Ácaros depredadores y Hongos entomopatógenos) para una posterior identificación en el laboratorio. Cuando las lechugas empezaban a acogollar y ya no se podían mirar bien las hojas de la planta, se realizó un muestreo destructivo de las mismas. Para la recogida de las muestras, que fueron preservadas en alcohol, se utilizaron pinceles, tubos de ensayo y botes de plástico de $120 \mathrm{ml}$. Para la identificación de los pulgones se utilizaron las claves REMAUDIERE (1990), BLACKMAN \& EASTOP (2000). Los parasitoides de pulgones fueron identificados empleando las claves STARY (1976) y PENNACCHIO (1989) y para la identificación de los Sírfidos, se utilizaron las claves de STUBBS \& FALK (2002). En todos los casos, la identificación fue revisada por especialistas en cada grupo de insectos.

\section{RESULTADOS}

Las principales especies de pulgones encontradas en el muestreo en los dos años de muestreo (otoño, 2003 y primavera, 2004) fueron Nasonovia ribisnigri (Mosley, 1841) (Figura 1), Macrosiphum euphorbiae (Thomas, 1878) (Figura 2) y en menor número Acyrthosiphon lactucae (Passerini, 1860). También se encontraron individuos de Uroleucon sonchi (Linnaeus, 1767) y Aphis sp. pero de forma muy esporádica y en número irrelevante comparado con las dos especies mencionadas anteriormente. Los principales grupos de parasitoides y depredadores encontrados en cada época de muestreo aparecen descritos en los siguientes apartados.

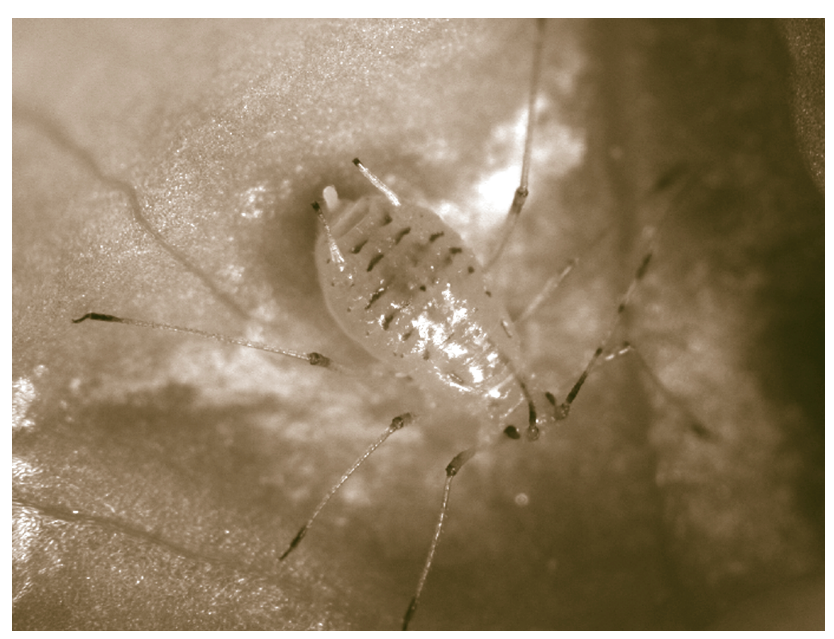

Figura 1. Nasonovia ribisnigri.

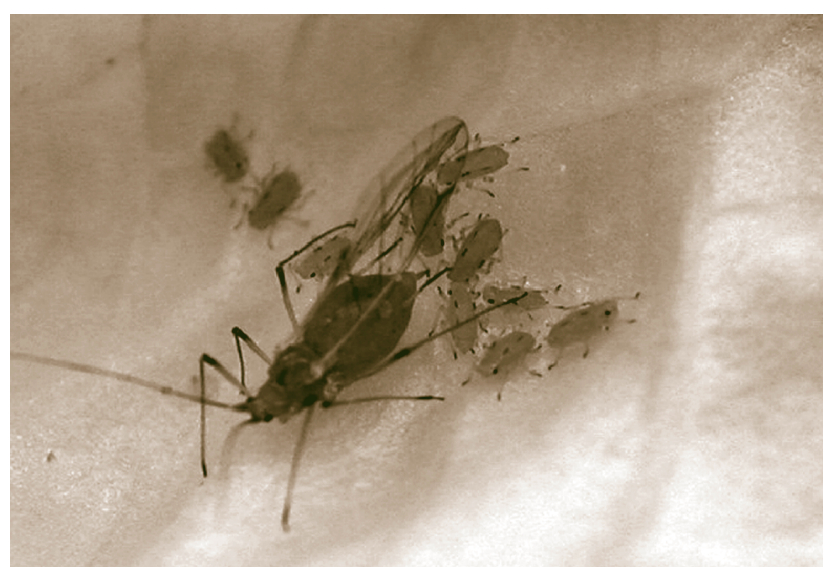

Figura 2. Macrosiphum euphorbiae. 


\section{OTOÑO 2003}

Se ha encontrado un elevado número de especies depredadoras de dichos pulgones, habiéndose identificado un total de 13 especies pertenecientes a: Orius (Hemiptera, Anthocoridae), estafilínidos (Coleoptera, Staphilinidae), míridos (Hemiptera, Miridae), anístidos (Prostigmata, Anystidae), fitoseidos (Mesostigmata, Phytoseiidae), sírfidos (Diptera, Syrphidae), coccinélidos (Coleoptera,
Coccinellidae) y crisopas (Neuroptera, Chrysopidae), destacando en número los representantes de Orius spp. (Hemiptera, Anthocoridae) y los Ácaros depredadores de las familias Anystidae (Prostigmata) y Phytoseiidae (Mesostigmata,). En la Figura 3 aparece representado el nivel relativo de abundancia a lo largo de la época de muestreo de cada uno de los grupos de depredadores y hongos entomopatógenos en relación con la dinámica poblacional de las poblaciones de pulgones existentes.

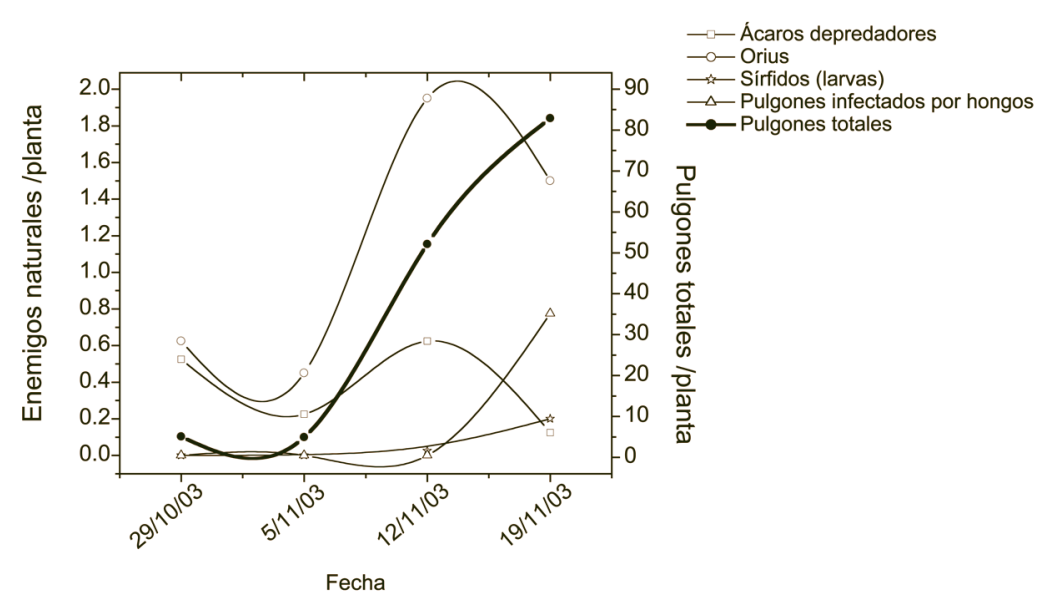

Figura 3. Dinámica poblacional de los principales grupos de enemigos naturales de los pulgones (eje izquierdo) y de los pulgones totales (suma total de todos los individuos presentes de las especies N. ribisnigri $y$ de M. euphorbiae) en el ensayo de otoño de 2003.

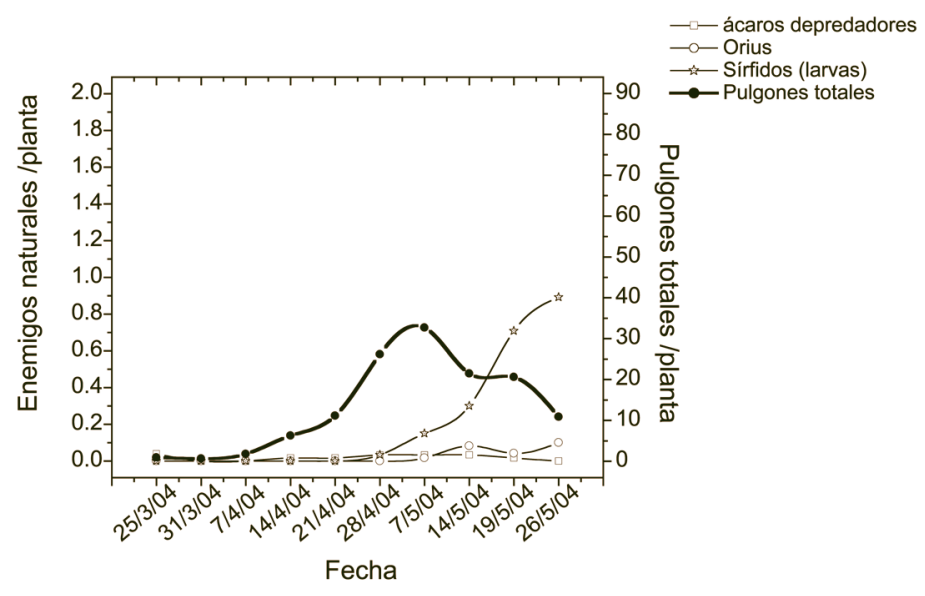

Figura 4. Dinámica poblacional de los principales grupos de enemigos naturales de los pulgones (eje izquierdo) y de los pulgones totales (suma total de todos los individuos presentes de las especies N. ribisnigri $y$ de M. euphorbiae) en el cultivo de primavera de 2004.

\section{PRIMAVERA 2004}

Los grupos de depredadores encontrados son también los mismos que los observados en otoño, pero en esta ocasión la riqueza relativa es mayor, siendo $17 \mathrm{el}$ número de especies depredadoras encontradas.

Durante el ciclo de cultivo de la lechuga el grupo de depredadores con mayor número de individuos por planta fue el de los sírfidos (Figura 4), habiéndose identificado las especies Sphaerophoria scripta (Linnaeus, 1758), Sphaerophoria rueppellii (Wiedemann, 1830), Episyrphus balteatus (De Geer, 1776) y Eupeodes corollae (Fabricius, 1794) (Figura 5). De las cuatro especies identifica-

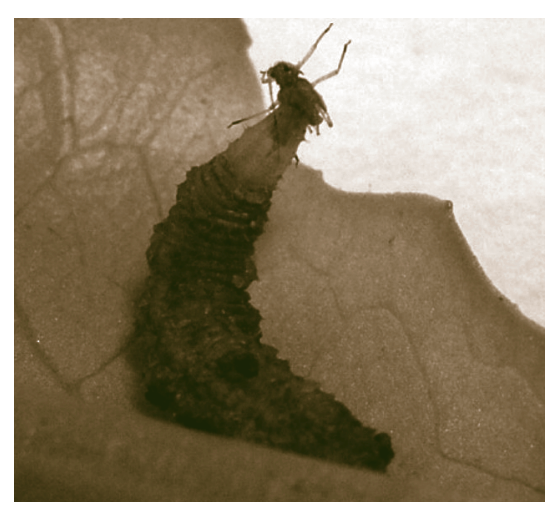

Figura 5. Larva del sírfido Eupeodes corollae alimentándose de una ninfa de Nasonobia ribisnigri. 
das, únicamente la primera se encontró en otoño del 2003. La especie E. corollae destacó en número sobre todas las demás constituyendo más del 50\% de las muestras recogidas de este grupo durante la primavera.

No obstante, el grupo de antagonistas biológicos de los pulgones que más abundó en primavera del 2004 fue, sin duda, el de los hongos entomopatógenos, provocando el descenso a la mitad de la población total de pulgones al final del ciclo del cultivo (26 de mayo). El día 19 de mayo se registró una media de 11,34 pulgones infectados por hongos por cada planta muestreada (Figura 6).

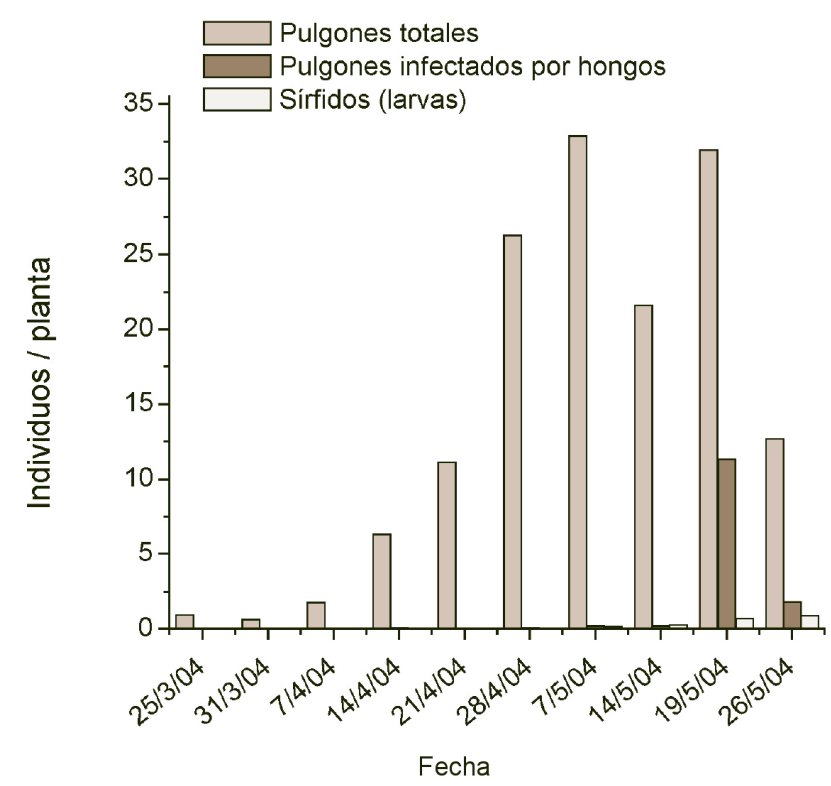

Figura 6. Dinámica poblacional de pulgones totales, hongos entomopatógenos y larvas de sirfidos por planta de lechuga en La Poveda durante la primavera de 2004.

\section{DISCUSIÓN}

La diversidad de los diferentes grupos de enemigos naturales de los pulgones en un mismo cultivo es muy amplia, lo que hace que aunque en un determinado momento las condiciones ambientales perjudiquen a algunos de ellos, otros puedan ser potenciados lo que asegura la presencia de enemigos naturales en situaciones bien distintas. Aunque los enemigos naturales encontrados no llegaron a controlar completamente por sí mismos las poblaciones de pulgones, el conocimiento de la fauna útil presente en los campos de cultivo, puede permitir potenciar la efectividad del control biológico y disminuir el número de tratamientos insecticidas que se aplican. Con ello se puede llegar a suprimir el riesgo a la resistencia de los pulgones a los distintos productos fitosanitarios y atenuar los problemas que se desprenden de su uso indiscriminado.

Los resultados observados en otoño nos permiten recomendar, como método complementario o alternativo a los insecticidas en un control integrado y en esta época del año, un control biológico utilizando las especies más comunes de Orius Wolf, 1811 que a juzgar por su abundancia, parecen estar bien adaptadas a los cultivos de lechuga en esta zona. En el caso de la primavera, las condiciones de humedad y temperatura que se dieron en el transcurso de este ensayo fueron óptimas para la aparición de epizootias causadas por hongos entomopatógenos. Sin embargo, en condiciones normales, dada la escasa humedad relativa de la zona, la recomendación más adecuada, puede ser la utilización de sírfidos, ya que hay que considerar que cada larva de sírfido de la especie E. corollae puede llegar a alimentarse de hasta ochocientos pulgones hasta evolucionar al estado adulto (GEUSEN-PFISTER, 1986). En años con primaveras húmedas, sin embargo, se debería también considerar un manejo de las especies vegetales de los márgenes del cultivo, no sólo seleccionando plantas insectario que sean atractivas y actúen como suplemento alimenticio para los sírfidos u otros enemigos naturales, sino también plantas que puedan potenciar la conservación de hongos entomopatógenos específicos de pulgones.

Estos resultados basados en el conocimiento de los enemigos naturales y de su biología, ofrecen soluciones válidas en las estrategias de control de pulgones en los cultivos de lechuga. No obstante, y a pesar de que por el momento no permiten prescindir completamente de los insecticidas, si pueden considerarse como una eficaz alternativa a su uso exclusivo, lo que sin duda redundará en una mayor diversidad de nuestros aliados, los enemigos naturales de estas plagas. 


\section{BIBLIOGRAFÍA}

BLACKMAN, R.L. \& EASTOP, V.F. 2000. Aphids on the world's crops. An identification and information guide. John Wiley and Sons. 466 p.

EILENBERG, J., HAJEK, A. \& LOMER, C. 2001. Suggestions for unifying the terminology in biological control. Biocontrol 46: 387-400.

FLINT M.L. \& DREISTADT, S.H., 1999. Natural enemies handbook. The illustrated guide to biological pest control. University of California. $154 \mathrm{p}$.

GEUSEN-PFISTER, H. 1987. Untersuchungen zur Biologie und zum Reproduktionsvermögen von Episyrhus balteatus Deg. (Dipt., Syrphidae) unter Gewächshausbedingungen. Zeitschrift für Angewandte Entomologie 104 (3): 261-270.

PENNACCHIO, F. 1989. The Italian species of the genus Aphidius Nees (Hymenoptera, Bra- conidae, Aphidiinae). Boll. Lab. Ent. Agr. Filippo Silvestri 46: 75-106.

REMAUDIÈRE, G. \& SECO, M.V., 1990. Claves de pulgones alados de la región mediterránea. Rústica. 2 Vol. 110 p.

STARY, P. 1976. Aphid parasites (Hymenoptera: Aphidiidae) of the Mediterranean Area. Dr. W. Junk, B.V. Publishers, The Hague. Trans Czechosl Acad Sci, Ser. Math. Nat. Sci 86(2): 1-95.

STUBBS, A. E. \& FALK, S. J. 2002. British hoverflies. British Entomological and Natural History Society, 469 p.

\section{AGRADECIMIENTOS}

Este trabajo ha sido subvencionado por la beca predoctoral del Ministerio de Ciencia y Tecnología: AGL2003-0753-C03-01 y forma parte de la Tesis Doctoral de I. Morales (BES-2004-5217). 